corrections to be made for geometry and $\gamma$-escape, and the 'total intrinsic efficiency' of a scintillation counter is exhaustively treated.

The chapter on dosimetry is confined to fundamental concepts and present trends when dealing with physically (physiologically) significant doses, and in Chapter 7 most ()xplicit details and instructions are given for people working with sources of and in excess of microcuries. There is a short historical account of the way the 'safe' exposure dose has been arrived at over the past thirty years culminating in the 1959 recommendations for operatives exposed to different kinds of radiations; it is good to note that the author and most health physicists dealing with people continuously employed in a radiation field divide even theso conservative figures by a further ten. The improved film meter is advocated for personnel monitoring, and many instruments for surveying are describod. General guidance is given for waste disposal and accidents. The health physicist-a new and rapidly growing profession-needs to know evory word of this account.

T. E. Allibone

\section{WORKING UNDER PRESSURE}

\section{Solids Under Pressure}

Edited by William Paul and Douglas Mi. Warschauer. (McGraw-Hill Series in Materials Science and Engineering.) Pp. xvii +478. (New York: MeGraw-Hill Book Company, Inc.; London: MeGraw-Hill Publishing Company, Ltd., 1963.) 116s. $6 d$.

A WIDE variety of investigations, which have boon conducted at high pressures, is reviewed in this book, but descriptions of high-pressure techniques are excluded almost ontirely-apart from special bibliography at the end.

Having chosen a connecting thread, the editors would seem to have pulled it, but the result is a book which is unusually easy and entertaining to read. This is in part due to the fact that, with a new parameter to be varied, the simplest properties of the simplest solids are the first objects of exploration. The bases of familiar theoretical models aro, therefore, probed afresh, and most of the chapters in this book involve re-statements of these basic models from slightly unfamiliar points of view (hence the entertainment).

My guess is that many physicists have the notion that the results of measurements at high pressures are only rarely of much significance, and that the experiments themselves are always of the brute-force varieties. This book would dispel such views. There are great difficulties in the way of achieving hydrostatic conditions at pressures in the megabar range, but up to 30 kilobars there is standard and not too elaborate equipment now available and measurements of high resolution and of several different kinds can be made. The same is true of prissures up to 100 kilobars in specialist laboratories. Pressure might not rival temperature as a parameter, the variation of which can produce large and significant ohanges in the behaviours of solids, but it is clearly catching up. This is a timely situation, because there is an increasing need to separate those parts of a change in behaviour with tempera. ture which are explicitly temperature-dependent, on one hand, and implicitly temperature-dependent (for example, via lattice expansion) on the other. Ancillary measurements at high prossures meke this possible and there are several examples in the book. The present-day theoretical concern with interactions between quasi-particles (latticewaves and spin-waves in particular) makes this separation particularly desirable.

Eightoen authors contribute fourteon chapters on equilibrium, transport and activation properties, and phase transitions, involving descriptions of optical, magnetic, elastic, thermal and othor measurements.
The whole book is addressed as a tribute to Prof. Bridgman, whose death regrettably preceded the publication. He contributed the introductory chapter, and the rest of the book illustrates the first steps in his vision of the future of high-pressure research as $a$ progressive delocalization of electrons in successive atomic shells.

D. H. Martin

\section{TEXTILE PHYSICS}

Physical Properties of Textile Fibres

By Prof. W. E. Morton and Dr. J. W. S. Hearle. Pp. xxi +608. (Manchester: The Textile Institute; London: Butterworth and Co. (Publishers), Ltd., 1962.) $105 s$.

A COMPENDIUM of information, dealing with a subject A wide onnugh for no one to be master of all of it, tends to be received with opposite comments according to the self-control of the reader. He is tempted to look first at the part dealing with his own speciality. Tho result will be a criticism-none of us approve of encyclopædia articles on our own subjects (unless, indeed, we have written them ourselves). But this is to misuse the book; its proper role is to help us to look up other people's subjects as may be nocessary, even if superficially, so that we do not have to pester our colleagues. Who, then, could safely write a book like this ? Obviously a teacher, for he alone in our sadly specialized world has to maintain more than a passing interost in all branches of his subject. The Physical Properties of Textile Fibres is just such a book, and it is fittingly written by a professor and a senior lecturer at the Manchester College of Science and Technology. It made a good first impression, and was accordingly subjected to the stringent test of being lent to various colleagues of mine with a request for their opinions on parts dealing with their own topics. In no case was thero an adverse report-this is high praise.

After an introductory chapter on fibre structure, which may be regarded as setting the background for the rest of the book, there is a long section on fibre dimensions and their measurement, followed by sections on density, moistur $\Theta$ relations and offects, mechanical, electrical, optical and thermal properties, and, finally, one on friction. Throughout, the treatment preserves a good balance between methods of measurement, results specific to particular fibres, and discussion of thoir meaning. Tho accounts of methods are critical where required, and attention is given to that especial plague of textile physics -variation in results-and how to deal with it. The methods of measurement described are not only those used in research laboratories; methods used in industry are given a fair share of attention, though in all cases the emphasis is on principles rather than on practical details (which are available elsewhere).

The book is well supplied with diagrams, and data are presented by graphs rather than tables wherever possible. Here arises ono of the few criticisms that can be made: where data are to be read from graphs in a book, it is convenient if the scale of reproduction is such that the units are simply related to contimetres or inches so that a ruler can be used without paper calculations. This is not often done, but it would be a welcome novelty. In the present book some 50 per cent of the graphs do comply with this requirement, but the remaining 50 per cent are reproduced just a littlo too big or too small. When the book comes to a well-deserved second odition, may we have these adjusted ?

The lists of references, always an important part of a book like this, are adequate so far as can roadily be soen, where faults are usually those of omission.

Occasional blemishes occur; for example, at the bottom of p. 105 some of the instrumental parts referred to by letter are not present in the appropriate diagram, and there are a fow rash statoments such as that in the last 